\title{
FAILURE PREDICTION OF PROPELLER-SHAFT PROTOTYPE USING FINITE ELEMENT ANALYSIS
}

\author{
R. K Praharaj ${ }^{1}$, N. Gadre ${ }^{2}$, A. Maharathy ${ }^{3}$ \\ ${ }^{I}$ Mechanical Engineering Dept. NIT, Rourkela, India \\ ${ }^{2}$ Mechanical Engineering Dept. VJTI, Mumbai, India \\ ${ }^{3}$ Mechanical Engineering Dept. IIT,Bhubaneswar, India
}

\begin{abstract}
A premature failure that occurs before the expected load cycle during the torsional fatigue test of a propeller shaft assembly prototype is studied. In these test crack mainly originated repetitively from one of the components, namely Flange yoke at same region. To determine the root reason of the failure a detail CAD model of Flange yoke was developed and analyzed by Finite Element Method. Fatigue crack initiation and location were determined and compared with test data. We found good correlation between FEM results with testing failure results. Design improvements solutions are proposed to increase the fatigue life. Mechanical properties of the Flange yoke were determined by the tensile strength test. Using these input datas stress and strain analysis was performed in ANSYS software.
\end{abstract}

Keywords: Finite Element Analysis, Stress Concentration, Structural Analysis

\section{INTRODUCTION}

A drive shaft or propeller shaft is a mechanical component which is used for transmitting power from the gear box to the differential in the vehicle. Propeller shaft is used as a connector between gearbox and differential as they are cannot be connected directly because of their position in the vehicle and also they need a relative motion between them. High torque is transmitted through the propeller shaft, so it is subjected to high torsion and shear stress, therefore propeller shafts should strong enough to bear these stresses also as it is a rotating component additional weight leads to increase mass moment of inertia. Generally propeller shaft assembly as shown in fig. 1 consists of many components, namely flange yoke, short fork, long fork, rear housing, universal joint cross and tube. Therefore a failure of one of the components leads to propeller shaft failure. Thus, all the components should bear the resisting torque independently. As per acceptance criteria, the propeller shaft should resist $1 \times 10^{\wedge} 5$ cycles without any failure, but it is observed that cycles before fatigue failure was about $1.6 \times 10^{\wedge} 4$

To predict the root reasons of earlier failure of flange yoke, a detailed 3D model of flange yoke was developed in CREO version 2 software. Finite element analysis was carried out on that model. The stress and strain analysis were carried out in ANSYS WORKBENCH V14.5. By this analysis induced high stress regions were obtained.

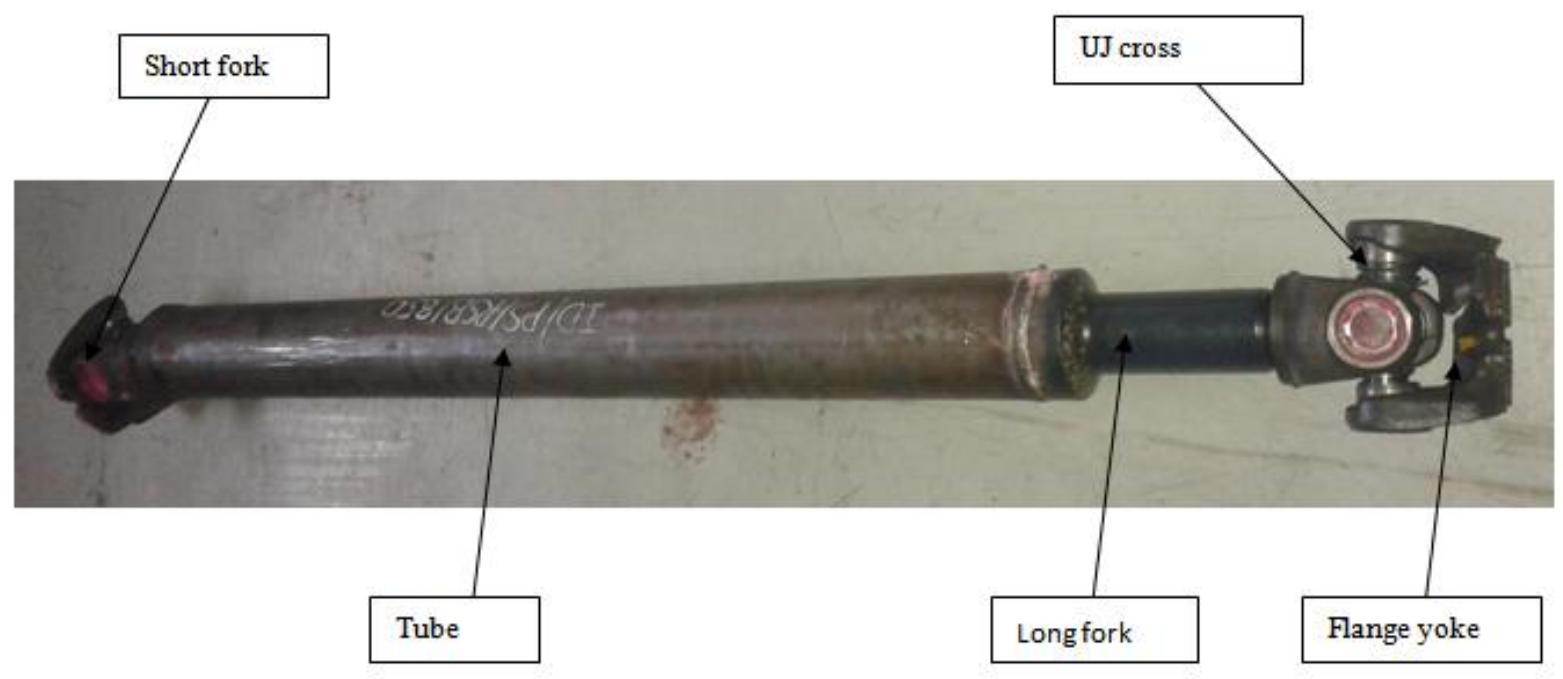

Fig.1 Propeller shaft assembly 


\section{PROBLEM DEFINATION}

This prototype propeller shaft was supposed to be designed for $5250 \mathrm{Nm}$ transmitting torque for transport commercial vehicles. During the validation, it was noticed that after 16,000 cycles, propeller shaft failed as shown in fig. 2. Only flange yoke component was broken during the testing as shown in fig. 3. There were three propeller shaft assembly were tested for validation but all propeller shafts were failed below 20000 cycles with similar failure pattern i.e in all cases flange yoke was failed. Crack initiation pattern were same for all the flange yoke. Scope of this study was to find the root cause behind the failure and to propose alternative way to avoid that failure.

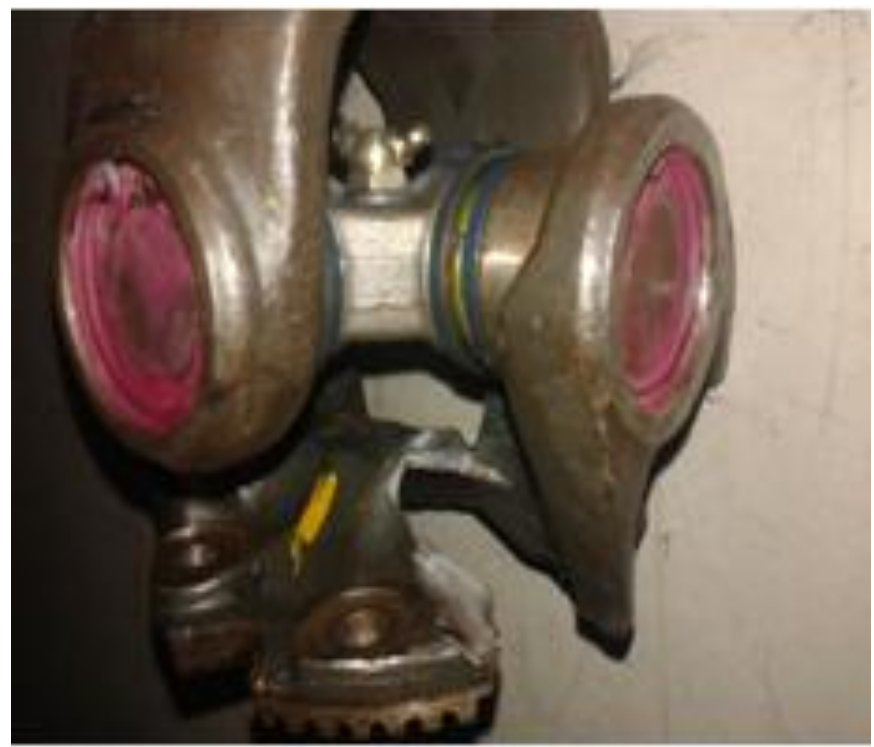

Fig.2 Failure snap of Propeller shaft

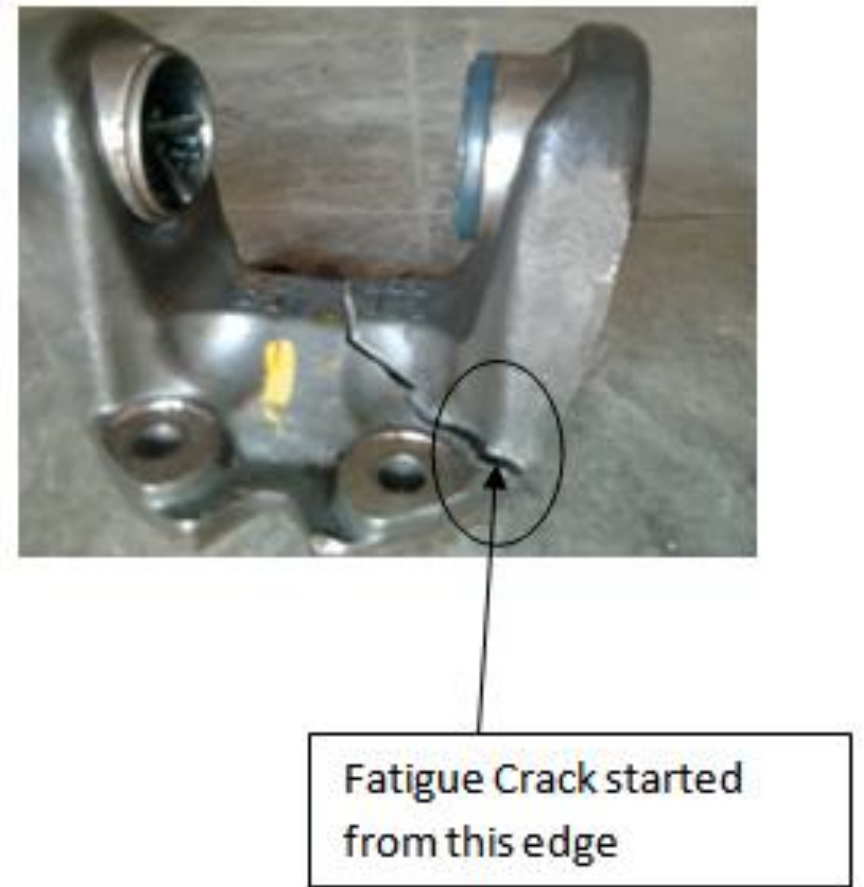

Fig.3 Failure snap of Flange yoke

\section{FINITE ELEMENT ANALYSIS}

A full scaled CAD model of flange yoke was prepared for the analysis as shown in fig 4. And imported to ANSYS WORKBENCH for constituting a FE model. To build the Finite Element Model, Flange yoke was meshed using solid 92, a higher order three dimensional solid element, which is suitable for the meshing irregular shape model. Solid 92 element has 10 nodes having three translational DOF at each node [2]. At critical region, finer meshing was done for better results. Finite Element model consisted of 103839 elements and 160311 nodes. Mechanical properties of the material as shown in below table1 were taken for static structural analysis.

Table1: Physical properties of $35 \mathrm{C} 8$

\begin{tabular}{|lcccc|}
\hline Material & Young's Modulus, E (GPA ) & Poisson's ratio, $\mu$ & Yield strength, Syt (MPa) & Ultimate \\
\hline $35 \mathrm{C} 8$ & 210 & 0.3 & 650 & 850 \\
\hline
\end{tabular}

\subsection{Loading and Bounadary Condition}

Loading and boundary condition applied to the flange yoke is shown in fig. 5 Here torque is applied to the mass node, which is connected to eye fork surface through the rigid elements. As this component is going to held by serration engagement with mating parts, so that restraint these engaged serrations faces only which resist the applied torque also it has to be restrained at the bolt sitting hole for axial movement where it is bolted with mating parts.

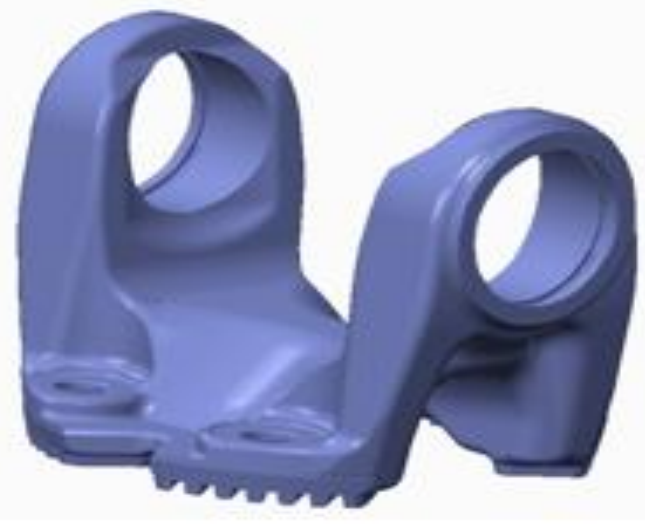

Fig. 4 CAD model of Flange yoke 


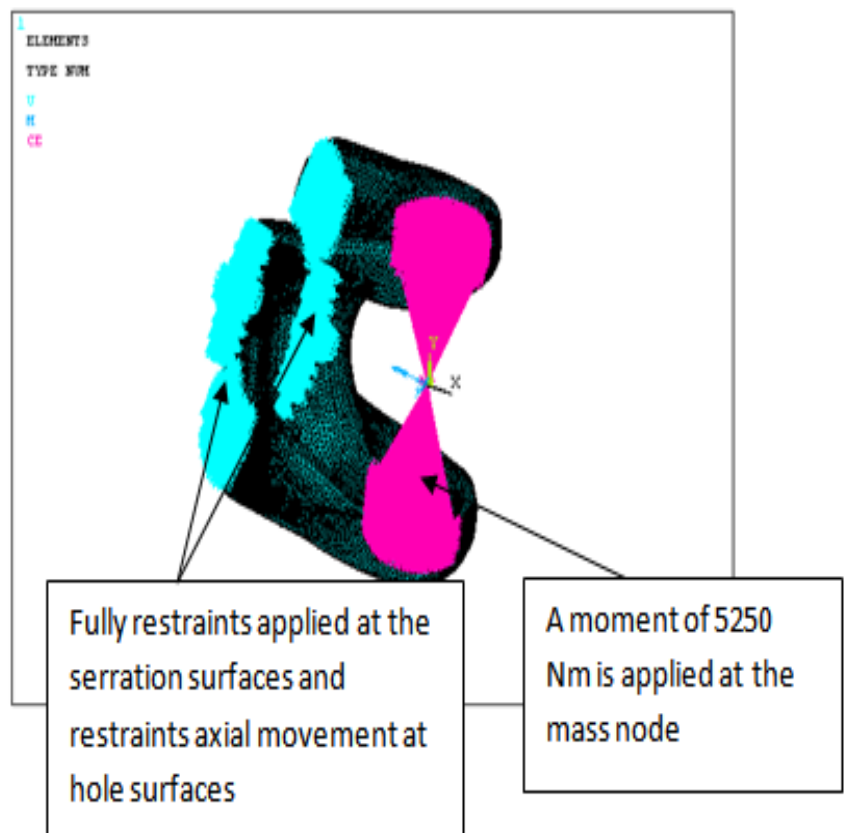

Fig. 5 loading and boundary condition applied on the FE model

\subsection{Result Interpitation}

From the Von-mises stress plot as shown in fig. 6, it is clearly seen that relatively high stress is induced at a bolt mounting area which promotes to crack initiation. We found that while testing, cracking was started from the bolt sitting region. Fig.8 shows the total displacement of flange yoke during loading. Fig.9. shows that the factor of safety distribution in the flange yoke and it is clearly seen that at the critical region factor of safety is close to zero, thus that region enhance to crack initiation.

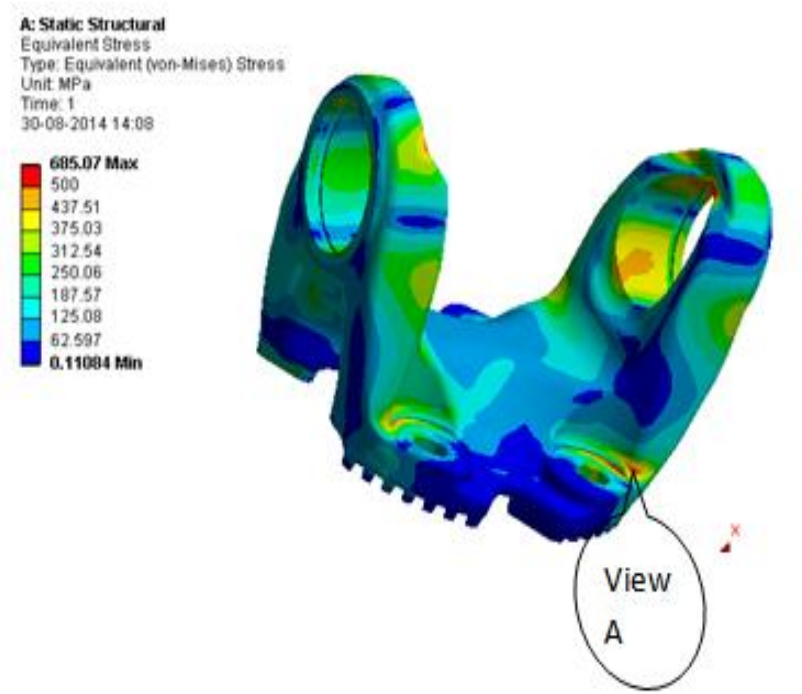

Fig. 6 shows von mises stress plot

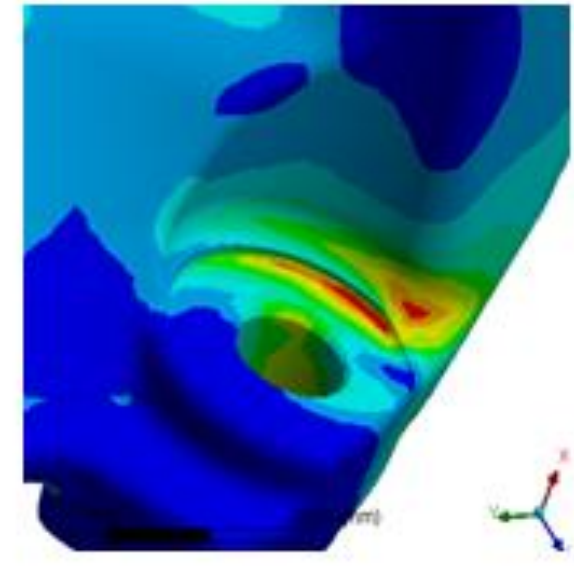

Fig.7 Shows zoom view A

A: Static Structural
Total Deformation
Type: Total Deformation
Unit: mm
Time: 1
30-08-2014 14:12
$\begin{aligned} & \mathbf{0 . 3 6 4 1} \text { Max } \\ & 0.32365 \\ & 0.28319 \\ & 0.24274 \\ & 0.20228 \\ & 0.16182 \\ & 0.12137 \\ & 0.080912 \\ & 0.040456 \\ & \mathbf{0} \text { Min }\end{aligned}$

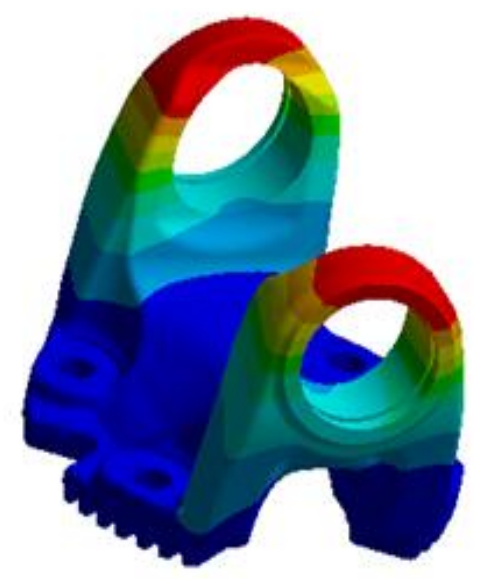

Fig.8 Shows total displacement plot
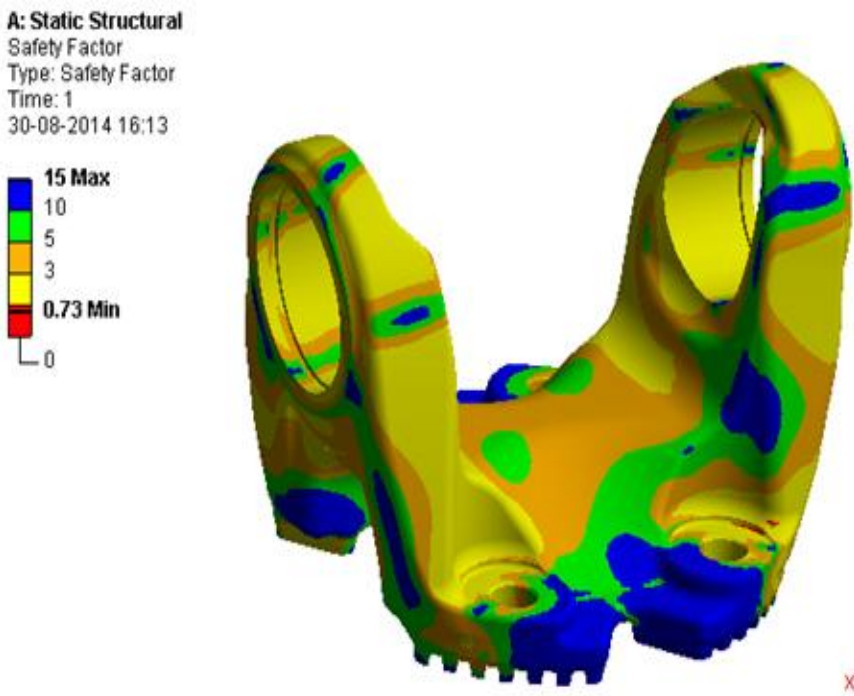

Fig. 9. Factor of safety distribution 


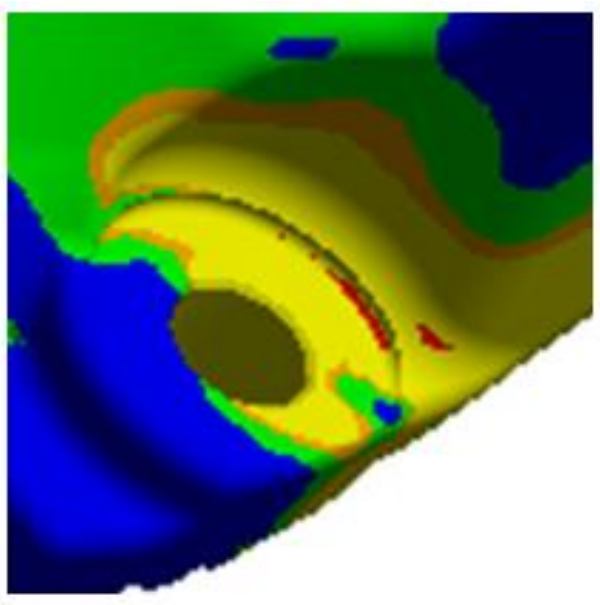

\section{RESULTS AND DISCUSSION}

FE analysis showed that the regions from which fatigue failure was initiated during the fatigue torsional test, are subjected to the stress concentration, which can cause a premature failure before the acceptance criteria of $1 \times 10^{\wedge} 5$ cycles. At the critical region, stress (620 MPa) was closed to the yield strength of the specified material also factor of safety close to zero. Critical regions which obtained in FE analysis are well agreeing with torsional test result. Increase of the fatigue life is dependent on the decrease in stress concentration. One of the easy way to reduce stress concentration and improve the fatigue life is adding material to increase the thickness of the rib at the bolting area. A proper fillet radius should give at that sharp transition zone, which can reduce stress concentration factor.

\section{CONCLUSION}

Premature fatigue failure of propeller shaft was investigated by using Finite Element Analysis. In this analysis torsional torque test was simulated. The stress concentration region was predicted at bolting sharp transition area. The region from which crack originated were well matched with the Finite Element Analysis results, thus by FE method the location of failure can be predicted.

In order to fix the problem, redesign is required in the critical region, increase the thickness of the rib at the bolting area and proper fillet radius should give to reduce stress concentration to obtain a longer fatigue life.

\section{REFERENCES}

[1]. Topac N.M,Gunal H, Kuralay N.S. Fatigue failure prediction of a rear axle housing prototype by using finite element analysis. Engineering failure Analysis 16 (2009) 1474- 1482

[2]. ANSYS Theory Reference. ANSYS Release 10.0 ANSYS, Inc.;2005

[3]. Jiang Y, Hertel O, Vormwald M. Experimental evaluation of three critical plane multiaxial fatigue criteria. Int J Fatigue 2007;29:1490-502.

[4]. R.S Khurmi, Machine design textbook, Chapter 6
[5]. Shigley JE. Mechanical Engineering design. Tokyo: McGraw -Hill Kogakusha

[6]. Gordon KW. Design, evaluation and selection of heavyduty rear axles. SAE Trans 1955;63:5-34.

[7]. Shigley JE, Mischke C. Mechanical engineering design. New York: McGraw-Hill; 1989. p. 286-8.

[8]. Lee YL, Pan J, Hataway R, Barkey M. Fatigue testing and analysis. New York: Elsevier Butterworth-Heinemann; 2005. p. 162.

[9]. Schijve J. Fatigue of structures and materials. Dordrecht, Netherlands: Kluwer Academic Publishers; 2001. p.68-72.

[10]. Smith M, Fisher F, Romios M, Es-Said OS. On the redesign of a shear pin under cyclic bending loads. Eng Fail Anal 2007; 